\title{
The Design and Implementation of HuangGang Normal University Dormitory Management System
}

\author{
Jingxiu $\mathrm{Xu}^{1, \mathrm{a}}$, and Dan Zhang ${ }^{2, \mathrm{~b}}$ \\ Huanggang Normal University, Huangzhou two, XingangDistrict, Huanggang City, Hubei Province, \\ China
}

Xujingxiu123@126.com, 401678580@qq.com

Keywords: Informatization; Dormitory management; Networked

\begin{abstract}
At present under the environment of whole society informatization, the informatization construction is reflected in all aspects of our campus. In recent years, the scale of our school has gradually expanded, so that the amount of student information becomes more and more huge, student dormitory management has always been an integral part of the school management work, the school dormitory management should be improved and got better. The Huanggang Normal College student dormitory management system this article expressed has the computer information, the network management characteristic, the backstage database storage capacity It provided is quite large, and is relatively stable, suitable for the long time preservation, not easy to lose. This is undoubtedly for the schools which have large student information storage to provide a convenient and efficient mode of operation, so that people from the heavy data processing and maintenance out of relief, replaced by a friendly interface, the design of a very user-friendly front Application, the user will feel very easy to operate
\end{abstract}

\section{Purpose of the Project Study}

At present under the environment of whole society informatization, the informatization construction is reflected in all aspects of our campus. In recent years, the scale of our school has gradually expanded, so that the amount of student information becomes more and more huge, student dormitory management has always been an integral part of the school management work, the school dormitory management should be improved and got better.

Traditional manual recording management has been far less than expected, not only cumbersome but also prone to error, and once the need to find some records will spend a lot of time and manpower, the efficiency is very low. This shows that the traditional dormitory management, that is staff manual records by dormitory manager has been unable to adapt to the current high-speed development of the information age, and we need a new way to retrieve the old manual way with features such as quick retrieval, easy searching, high reliability, and large storage capacity.

Student dormitory management computer informatization, network management is based on this management inefficient environment, the resulting an ideal choice. The backstage database storage capacity It provided is quite large, and is relatively stable, suitable for the long time preservation, not easy to lose. This is undoubtedly for the student information storage capacity of the larger schools to provide a convenient and efficient mode of operation, so that people from the heavy data processing and maintenance out of relief, replaced by a friendly interface, the design of a very user-friendly front Application, the user will feel very easy to operate ${ }^{[1]}$ 。

\section{The Significance of This Project}

Combined with the project research purposes above mentioned, the design and implementation of the dormitory management system are mainly manifested in the following aspects:

the new semester at school, you can achieve the registration of student information and modify the relevant information to facilitate the new counselors allocating the dormitory.

each school year can be convenient for students to register, to facilitate the teacher to check the 
dormitory payment situation.

in order to ensure the safety of the campus dormitory, the visitors information should be unified input in system, and make finished visiting information entry work, this has a certain significance to the campus dormitory safety.

When students' goods out of the building, but also need to the system entry registration, to prevent students dormitory items were stolen, with a certain degree of security significance.

to achieve real-time online management, reduce the blindness of the work, improve the professional quality of the staff.

\section{Development Goals and Ideas}

After the investigation of several college dormitories in the vicinity, the development goal is: a dormitory management system can provide dormitory management personnel with sufficient information and quick inquiry method, requires a program interface friendly, functional and other characteristics .In the system to achieve the allocation of students for the dormitory, student accommodation, student information, Building information, dormitory information and daily management information, add, modify, delete, statistical query and the results output function.

The system is a multi-user system, by setting different levels of users to distinguish between their operating authority on the system. Here, the user is divided into two types of "administrator" and "student". The administrator has all the operational privileges on the system, and the student can only modify the personal information and query the operation of the information.

\section{System Analysis}

\section{Feasibility Study of the Subject}

Technical feasibility: the system through Visual Studio 2010 and large databases SQL Server 2005 powerful features to develop and implement. Visual Studio 2010, introduced by Microsoft, provides an object-oriented environment designed for data structure and application environment development. It is powerful and easy to use. Whether it's organizing information, running queries, creating integrated relational data, or writing end-user functionality, comprehensive data management applications, Visual Studio 2010 can provide all the tools you need [3]. SQL Server 2005 provides users with a complete database solution that helps a variety of users build their own business systems and enhance their ability to respond to changes in the outside world in order to improve the user's competitiveness. SQL Server 2005 is the version of SQL Server Database Management System that Microsoft introduced in 2005. It is an outstanding database platform for large online transaction processing, data warehousing, and e-commerce.

Requirements Analysis

This stage requires users to visit, access to information and other means to understand the user's work flow. And as a basis to determine the function of the system to build the logical model of the system. Finally complete system conceptual structure design and data analysis. After investigation and combined with the actual situation, the following aspects must be taken into account in the student dormitory management system:

a. Student information management

The function module mainly includes: adding student information (including student ID, name, sex, department, class, telephone, political face and other information); modify student information (that is, To modify the student's information); Dormitory allocation (for newly added students can be allocated dormitory priority or student priority); student dormitory accommodation (you can delete a designated student, and cancel the school number and name).

b. Dormitory information management

The function module mainly includes: dormitory information (for dormitory information such as dormitory number, the number of people can live in, sex, price, dormitory phone, etc.) add, modify, delete, dormitory score (to achieve the dormitory number, How many weeks, the year to score );

c. Access registration management 
The function module can submit the status of the visiting registration information (interviewee, visitor, relationship, interviewee dwelling number, name of the document, date of visit), the end of the visit information (interviewee, visitor, relationship, interviewee dwelling number, name of the document, date of visit), Cargo out registration information (student ID, item, name, document name, shipping date) to submit.

d. Query management

The function module can query the dormitory information (dormitory number, the number of people can live in, the number of live in, living sex, price, status, etc.), student status information (student ID, name, sex, political appearance, department, class), visit information (Start date, end date, visitor name, interviewee name, guest dormitory, affiliated relationship, name of the document, visiting time, etc.), Cargo out information (start date, end date, student ID, name, Cargo, the name of the document, the time to go out, The man on duty, etc.), excellent dormitory information.

e. System Management

The function module includes: user management (including add / delete users, administrator password modification); user level selection.

\section{f. Help}

The function module mainly to view the system information and exit the system。

Data Table Design

The system can design two important data tables, the tables are as follows:

Table 1 Dormitory information table

\begin{tabular}{|c|c|}
\hline Column name & data type \\
\hline Bedroom number & nchar(6) \\
\hline Number of people can live in & Int \\
\hline Actual residence & Int \\
\hline Residential Sex & Nchar(2) \\
\hline Price & Numeric(9,4) \\
\hline state & Nchar(5) \\
\hline Dormitory phone & nchar(8) \\
\hline
\end{tabular}

Table 2 Dormitory assignment information table

\begin{tabular}{|c|c|}
\hline Column name & data type \\
\hline Student ID & nchar(12) \\
\hline Student name & nchar(10) \\
\hline Dormitory number & nchar(6) \\
\hline Bed number & nchar(2) \\
\hline Remarks & nchar(12) \\
\hline
\end{tabular}

\section{System Design and Key Technology Implementation}

The design of the system is to use Brower / Server architecture, that is, customer networking using WEB browser to carry out the operation of new students dormitory management.

The key technology of the system is to use the dormitory allocation algorithm, the basic idea is: first of all, according to the situation of the school dormitory, different professional dormitories will be set up for the male and female dormitory, and thus generate the dormitorys and beds. And then according to the admission situation of new students allocate to pre-assigned dormitory (the number of professional boys and girls admitted). Pre-allocation of dormitory algorithm is very simple, such as a professional number of boys is exactly an integer multiple of 6 , the integer is $n$, then allocate $n$ dormit

ory, if there are remainders, and greater than or equal to 3 , then $n+1$ dormitory, otherwise to allocate $\mathrm{n}$ dorms. 
This algorithm in the actual operation process, there are some need to adjust the strategy. Such as new students after the exchange of professional need to adjust the dormitory, or new students want to adjust the bed and so on.

\section{Summary}

This system is designed and developed for the problems existing in the management of students' dormitory in Huanggang Normal University. It has the characteristics of convenient operation, fast speed, stable operation, easy maintenance and practicality. It can reduce the workload of school dormitory managers and improve logistics Departmental management level and efficiency.

\section{Acknowledgements}

2016 Hubei University Students Innovation and Practice Training Program (The Design And Implementation Of HuangGang Normal University Dormitory Management System )

\section{References}

[1] Stephen Haag, Maeve Cummings, Yan Jianyu(translator), etc. Information Age Management Information System [M]. Beijing: CHINA MACHINE PRESS, 2011.

[2] Xu Yafeng, Jiang Xiaofeng. Design and Implementation of Interactive University Information System Based on .NET Platform [J]. SOFTWARE, 2013,34 (2): 7-9.

[3] Lan Yang, Jiang Shunye. FMS production management system based on asp.net [J]. SOFTWARE, 2013,34 (5): 76-78.

[4] Xia Huijun, Wei Xuehui. Easy to understand ajax [M]. Beijing: PUBLISHING HOUSE OF ELECTRONICS INDUSTRY, 2007.

[5] [the United States] matthew macdonald; mario szpuszta.ASP.NET3.5 Advanced Programming: 2nd Edition [M]. Booz \& Company, translated. Beijing: POSTS \& TELECOM PRESS, 2008.

[6] NPOI official website. Http: //npoi.codeplex.com [EB / OL]. 